\title{
Redesign Sistem Peredam Sekunder dan Analisis Pengaruh Variasi Nilai Koefisien Redam Terhadap Respon Dinamis Kereta Api Penumpang Ekonomi (K3)
}

\author{
Dewani Intan Asmarani Permana dan Harus Laksana Guntur \\ Departemen Teknik Mesin, Fakultas Teknologi Industri, Institut Teknologi Sepuluh Nopember (ITS) \\ e-mail: haruslg@me.its.ac.id
}

\begin{abstract}
Abstrak-Kereta api merupakan salah satu jasa angkutan umum darat yang sangat diminati. Medan yang dilalui oleh kereta api akan menimbulkan getaran yang dapat menyebabkan penumpang merasa kurang nyaman. Untuk itu perlu adanya pengembangan sistem suspensi sekunder sekunder kereta api untuk mencapai respon yang diinginkan, yaitu kenyamanan bagi penumpang kereta dengan kondisi medan yang bervariasi maupun saat terjadi perubahan kecepatan. Dalam penelitian ini, dilakukan pemodelan dan simulasi dari perubahan parameter yang ada pada sistem seperempat kendaraan kereta api dengan memvariasikan nilai koefisien redaman dan memodifikasi diameter orifice berdasarkan gaya redam sistem suspensi sekunder kereta api terhadap displacement maupun kecepatan. Simulasi dilakukan dengan menggunakan software Matlab dengan input sinusoidal. Frekuensi sistem suspensi divariasikan dari $0.5 \mathrm{~Hz}$ hingga $2 \mathrm{~Hz}$ dengan kenaikan setiap $0.5 \mathrm{~Hz}$. Dari hasil simulasi didapatkan bahwa nilai konstanta redaman sebesar 40700 Ns/m memiliki respon yang paling baik, yaitu pada kecepatan $50 \mathrm{~km} / \mathrm{jam}$ hingga $100 \mathrm{~km} / \mathrm{jam}$ ditinjau dari respon perpindahan, kecepatan, maupun percepatan yang dialami oleh sistem suspensi sekunder kereta api. Berdasarkan RMS perpindahan, RMS percepatan, maupun bode diagram dari sistem kendaraan dengan variasi konstanta redaman sebesar $40700 \mathrm{Ns} / \mathrm{m}$ juga merupakan yang paling baik jika dibandingkan dengan konstanta redaman lainnya. Pada sistem suspensi sekunder, perubahan variasi diameter orifice mempengaruhi besarnya gaya redam. Variasi diameter paling kecil menghasilkan nilai gaya redam yang paling besar. Selain itu, variasi diameter sebesar 2,356 mm merupakan nilai yang paling sesuai untuk dipasangkan pada sistem kendaraan kereta api dengan konstanta redaman sebesar $40700 \mathrm{Ns} / \mathrm{m}$.
\end{abstract}

Kata Kunci-bogie, sistem suspensi sekunder, diameter orifice, koefisien redam.

\section{PENDAHULUAN}

$\mathrm{E}$ RA globalisasi semakin menuntut manusia untuk bergerak lebih cepat. Oleh karena itu, kehidupan manusia di zaman modern ini tidak pernah lepas akan kebutuhan jasa transportasi. Dalam bidangnya, transportasi terbagi menjadi tiga bagian, yakni darat, laut, dan udara. Kereta api merupakan salah satu alternatif jasa angkutan umum darat yang masih sangat diminati. Hal ini menuntut perkeretaapian di Indonesia untuk meningkatkan kuliatas dari kereta api. Sebagai transportasi massal dengan durasi perjalanan relatif panjang, kereta api hendaknya memiliki tingkat kenyamanan yang tinggi bagi para penumpang. Medan yang dilalui oleh kereta api akan menimbulkan getaran yang menyebabkan para penumpang merasa kurang nyaman. Pada kereta penumpang, getaran tesebut diredam oleh sistem suspensi yang terdiri dari suspensi primer dan suspensi sekunder. Kriteria getaran yang dapat diterima oleh penumpang kendaraan telah tercantum dalam ISO 2631 [1]. Demi memenuhi kriteria yang telah ditetapkan pada ISO 2631, perlu adanya pengembangan sistem suspensi sekunder kereta api untuk mencapai respon yang diinginkan, yaitu kenyamanan bagi penumpang kereta dengan kondisi medan yang bervariasi maupun saat terjadi perubahan kecepatan dan perubahan massa muatan.

Salah satu cara untuk meningkatkan performa pada sistem suspensi sekunder kereta api yakni dengan memodifikasi nilai koefisien redaman pada sistem suspensi sekunder kereta api. Nilai koefisien redaman didapatkan dari hasil pemodelan dinamis sistem $1 / 4$ kendaraan kereta api lalu disimulasikan dengan Simulink. Grafik yang diperoleh dari hasil simulasi akan dianalisis hingga mendapatkan nilai koefisien redaman yang paling efektif ditinjau dari segi kenyamanan. Berdasarkan nilai koefisien redaman tersebut kemudian akan dirancang dimensi yang sesuai sehingga memenuhi kebutuhan.

\section{URAIAN PENELITIAN}

Dalam penelitian ini akan dianalisis respon dinamis dari sistem seperempat kendaraan kereta api berdasarkan variasi nilai koefisien redaman dan frekuensi, serta memodifikasi diameter orifice berdasarkan gaya redam sistem suspensi sekunder kereta api terhadap displacement maupun kecepatan. Penelitian ini dimulai dengan memodelkan sistem seperempat kendaraan kereta api. Berikut ini adalah pemodelan fisik dan dinamis dari sistem seperempat kendaraan kereta api. 

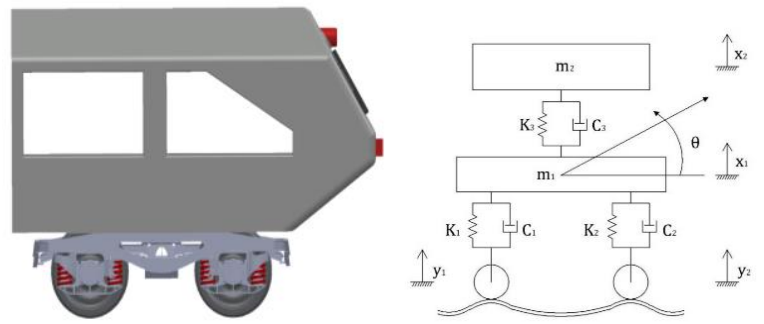

Gambar 1. Model fisik dan dinamis sistem seperempat kendaraan kereta api.

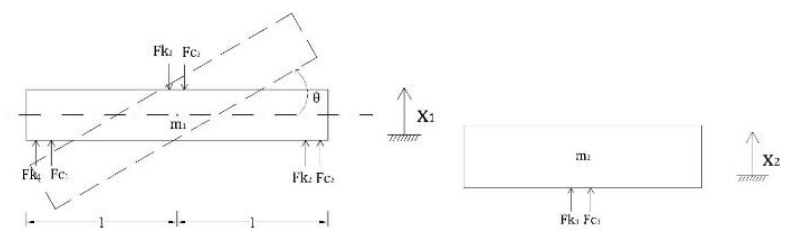

Gambar 2. Free Body Diagram sistem seperempat kendaraan kereta api.
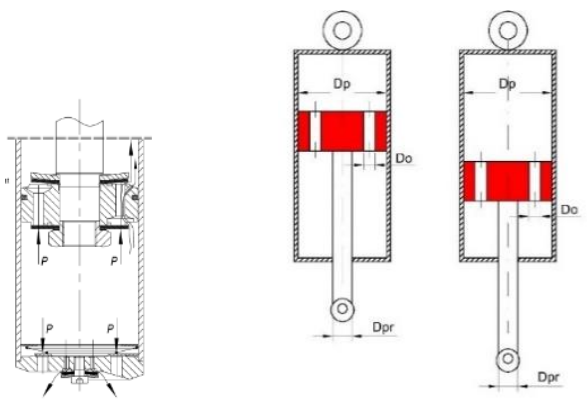

Gambar 3. Model fisik dan dinamis sistem suspensi hidrolik.

Tabel 1.

Parameter Free Body Diagram

\begin{tabular}{|c|c|}
\hline Simbol & Keterangan \\
\hline$K_{1}$ & Konstanta kekakuan dari suspensi primer $1(\mathrm{~N})$ \\
\hline$F k_{1}$ & Gaya pegas dari suspensi primer $1(\mathrm{~N})$ \\
\hline$K_{2}$ & Konstanta kekakuan dari suspensi primer $2(\mathrm{~N})$ \\
\hline$F k_{2}$ & Gaya pegas dari suspensi primer $2(\mathrm{~N})$ \\
\hline$K_{3}$ & Konstanta kekakuan dari suspensi sekunder $(\mathrm{N})$ \\
\hline $\mathrm{Fk}_{3}$ & Gaya pegas dari suspensi sekunder $(\mathrm{N})$ \\
\hline$C_{1}$ & Konstanta redaman dari suspensi primer $1(\mathrm{~N})$ \\
\hline$F c_{1}$ & Gaya redam dari suspensi primer $1(\mathrm{~N})$ \\
\hline$C_{2}$ & Konstanta redaman dari suspensi primer $2(\mathrm{~N})$ \\
\hline$F c_{2}$ & Gaya redam dari suspensi primer $2(\mathrm{~N})$ \\
\hline$C_{3}$ & Konstanta redaman dari suspensi sekunder $(\mathrm{N})$ \\
\hline$F c_{3}$ & Gaya redam dari suspensi sekunder $(\mathrm{N})$ \\
\hline$X_{1}$ & Displacement dari suspensi primer (m) \\
\hline$X_{2}$ & Displacement dari suspensi sekunder (m) \\
\hline$Y_{1}$ & Displacement dari base roda depan (m) \\
\hline$Y_{2}$ & Displacement dari base roda belakang $(\mathrm{m})$ \\
\hline$\theta$ & Sudut rolling pada suspensi primer (derajat) \\
\hline 1 & Jarak pusat bogie pada setiap suspensi (N) \\
\hline
\end{tabular}

Setelah mendapatkan model dinamis seperti Gambar 1, maka dibuat free body diagram seperti Gambar 2.

Berdasarkan Gambar 2, maka dibuat persamaan gerak sebagai berikut :

a. Massa translasi suspensi primer

$$
\begin{aligned}
& \sum F=M_{1} \overline{\mathrm{X}}_{1} \\
& F_{c 1}+F_{c 2}-F_{c a}+F_{k 1}+F_{k 2}-F_{k a}=M_{1} \ddot{\mathrm{X}}_{1}
\end{aligned}
$$

b. Massa rotasi suspensi primer

$$
\begin{aligned}
& \sum M_{1}=J \theta \\
& F_{e 1} \cdot l-F_{e 2} \cdot l+F_{k 11} \cdot l-F_{k 22} \cdot l=j \theta
\end{aligned}
$$

c. Massa translasi suspensi sekunder

$$
\begin{aligned}
& \sum F=M_{2} \ddot{\mathrm{X}}_{2} \\
& F_{C a}+F_{k 3}=M_{2} \ddot{\mathrm{X}}_{2}
\end{aligned}
$$

Tabel 1 merupakan parameter pada persamaan gerak sistem seperempat kendaraan kereta api dan Gambar 3 merupakan pemodelan fisik dan dinamis dari sistem suspensi sekunder.

Berikut adalah langkah-langkah perumusan gaya redam yang didapatkan dari hukum Pascal:

$$
F=\Delta P . A
$$

Mencari perumusan perbedaan tekanan dengan prinsip Bernoulli :

$$
P_{0}+\frac{1}{2} \rho V_{0}^{2}+\rho g z_{0}=P_{p}+\frac{1}{2} \rho V_{p}^{2}+\rho g z_{p}
$$

Mencari perbedaan tekanan pada penelitian diasumsikan $z_{o}=$ $z_{p}$, , sedangkan $g$ dianggap sama, maka persamaan menjadi :

$$
\begin{aligned}
& \frac{P_{p}-P_{\omega}}{\rho}=\frac{V_{0}^{2}-W_{p}^{2}}{2} \\
& \Delta P=\frac{\rho}{2}\left(V_{0}^{2}-V_{p}^{2}\right)
\end{aligned}
$$

Dari hukum konservasi massa didapatkan persamaan sebagai berikut :

- Ekspansi

$$
\begin{aligned}
F_{D} & =\Delta P \cdot A_{e} \\
F_{D} & =\frac{\rho}{2}\left(V_{0 e}{ }^{2}-V_{p}{ }^{2}\right) A_{e} \\
F_{D} & =\frac{\rho}{2}\left(\left(\frac{A_{p}}{A_{0 x}} V_{p}\right)^{2}-V_{p}{ }^{2}\right)\left(A_{p}-A_{p r}\right) \\
F_{D} & =\frac{\rho}{2}\left(A_{p}-A_{p r}\right) v_{p}{ }^{2}\left(\left(\frac{A_{p}}{A_{0 x}}\right)^{2}-1\right) \\
F_{D} & =\frac{1}{2} \rho\left(A_{p}-A_{p v}\right)\left(\left(\frac{A_{p}-A_{p r}}{A_{0 m}}\right)^{2}-1\right) x^{2}
\end{aligned}
$$

- Kompresi

$$
\begin{gathered}
F_{D}=\Delta P \cdot A_{k} \\
F_{D}=\frac{\rho}{2}\left(V_{0 k}^{2}-V_{p}^{2}\right) A_{k} \\
F_{D}=\frac{\rho}{2}\left(\left(\frac{A_{p}}{A_{0 k}} V_{p}\right)^{2}-V_{p}^{2}\right) A_{p} \\
F_{D}=\frac{\rho}{2}\left(\left(\frac{A_{p}}{A_{0 k}}\right)^{2}-1\right) A_{p} V_{p}^{2} \\
F_{D}=\frac{\rho}{2} A_{p}\left(\left(\frac{A_{p}}{A_{0 k}}\right)^{2}-1\right) \dot{x}^{2}
\end{gathered}
$$

Setelah mendapatkan persamaan gerak dari sistem seperempat kendaraan kereta api dan penurunan rumus dari sistem suspensi hidrolik langkah selanjutnya yaitu membuat blok diagram berdasarkan pemodelan yang telah dilakukan untuk melakukan simulasi pada MATLAB. Simulasi pada sistem seperempat kendaraan menggunakan input sinusoidal pada variasi nilai konstanta redam dengan variasi damping ratio 0.01 hingga 0.5 dan variasi kecepatan $20 \mathrm{~km} / \mathrm{jam}$ hingga $80 \mathrm{~km} / \mathrm{jam}$ dengan kenaikan $20 \mathrm{~km} / \mathrm{jam}$. Sedangkan sistem suspensi hidrolik pada variasi dimeter orifice $1 \mathrm{~mm}$ hingga 3 $\mathrm{mm}$ dan variasi frekuensi mulai dari $0.5 \mathrm{~Hz}$ hingga $2 \mathrm{~Hz}$ dengan kenaikan $0.5 \mathrm{~Hz}$. Semua simulasi menggunakan amplitudo jalan $0.02 \mathrm{~m}$. Parameter-parameter untuk melakukan simulasi terdapat pada Tabel berikut : 
Tabel 2.

Parameter sistem seperempat kendaraan

\begin{tabular}{lcc}
\hline \hline \multicolumn{1}{c}{ Parameter } & Nilai & Keterangan \\
\hline $\begin{array}{l}\text { Massa carbody }(\mathrm{m} 1) \\
\text { Massa bogie }(\mathrm{m} \text { 2) }\end{array}$ & $10000 \mathrm{~kg}$ & $\mathrm{~m} 1$ \\
$\begin{array}{l}\text { Koefisien pegas suspensi primer } \\
\text { (k1\&k2) }\end{array}$ & $1500 \mathrm{~kg}$ & $\mathrm{~m} 2$ \\
$\begin{array}{l}\text { Koefisien damping suspensi } \\
\text { primer (c1\&c2) (parameter }\end{array}$ & $150.000 \mathrm{~N} / \mathrm{m}$ & $\mathrm{k} 1$ \& k2 \\
$\begin{array}{l}\text { awal) } \\
\begin{array}{l}\text { Koefisien pegas suspensi } \\
\text { sekunder (k3) }\end{array}\end{array}$ & $\mathrm{c} 1$ \& c2 \\
$\begin{array}{l}\text { Koefisien damping suspensi } \\
\text { sekunder (c3) }\end{array}$ & $400.000 \mathrm{~N} / \mathrm{m}$ & $\mathrm{k} 3$ \\
\hline \hline
\end{tabular}

Tabel 3 .

Parameter sistem suspensi hidrolik

\begin{tabular}{ccccc}
\hline \hline $\begin{array}{c}\text { Massa } \\
\text { jenis } \\
\text { fluida } \\
(\rho)\end{array}$ & $\begin{array}{c}\text { Diameter } \\
\text { orifice (Doe) } \\
\text { (parameter } \\
\text { awal) }\end{array}$ & $\begin{array}{c}\text { Diaameter } \\
\text { piston (Dp) }\end{array}$ & $\begin{array}{c}\text { Diameter } \\
\text { piston rod } \\
\text { (Dpr) }\end{array}$ & Frekuensi \\
\hline & $0.001 \mathrm{~m}$ & & & $0.5 \mathrm{~Hz}$ \\
860 & $0.002 \mathrm{~m}$ & $0.05 \mathrm{~m}$ & $0.0354 \mathrm{~m}$ & $1 \mathrm{~Hz}$ \\
$\mathrm{~kg} / \mathrm{m}^{3}$ & $0.002368 \mathrm{~m}$ & & & $1.5 \mathrm{~Hz}$ \\
& $0.003 \mathrm{~m}$ & & & $2 \mathrm{~Hz}$ \\
\hline \hline
\end{tabular}

Dari pemodelan dan simulasi pada sistem seperempat kendaraan kereta api didapatkan grafik respon dinamis yang berupa respon perpindahan, kecepatan, dan percepatan yang dialami oleh kendaraan terhadap waktu. Kemudian grafik respon dinamis tersebut dianalisis dan dibandingkan dengan nilai RMS percepatan yang telah disimulasikan. Nilai RMS tersebut lalu diplot pada grafik ketahanan berkendara ISO 2631 untuk dianalisis ketahanan kendaraan berdasarkan waktu yang digunakan sebagai parameter pada simulasi sistem suspensi sekunder kereta api. Dari simulasi sistem suspensi sekunder didapatkan grafik gaya redam terhadap perpindahan dan kecepatan. Grafik gaya redam tersebut dianalisis, kemudian dipilih gaya redam terbaik untuk memilih diameter yang paling cocok sehingga lebih mampu mengurangi getaran pada carbody kereta api akibat energi eksitasi dari permukaan jalan yang tidak rata.

\section{HASIL DAN ANALISIS}

Dalam pemodelan ini didapatkan respon dinamis dari sistem seperempat kendaraan kereta api dan sistem suspensi sekunder terhadap variasi yang dilakukan. Respon dinamis dari pemodelan dan simulasi akan dijabarkan pada sub-bab dibawah ini.

\section{A. Respon Dinamis Kendaraan dari Sistem Seperempat Kendaraan Kereta Api Tipe Ekonomi}

Input sinusoidal digunakan untuk melihat respon dinamis sistem seperempat kendaraan akibat beban harmonik, serta untuk melihat waktu yang dibutuhkan sistem untuk mencapai kondisi steady state. Variasi kecepatan yang digunakan 20 $\mathrm{km} / \mathrm{jam}, 40 \mathrm{~km} / \mathrm{jam}, 60 \mathrm{~km} / \mathrm{jam}, 80 \mathrm{~km} / \mathrm{jam}$, dan $90 \mathrm{~km} / \mathrm{jam}$

Grafik pada gambar 3, 4, dan 5 menunujukkan hasil dari simulasi respon dinamis yang dialami oleh carbody kereta api pada kecepatan $90 \mathrm{~km} / \mathrm{jam}$, sedangkan data nilai dari respon dinamis tersebut terdapat pada tabel 8. Dari grafik dan tabel tersebut menunjukkan bahwa sistem suspensi dengan nilai konstanta redaman paling rendah memiliki respon kendaraan yang paling baik dibandingkan variasi lainnya dikarenakan memiliki nilai perpindahan yang lebih kecil. Untuk variasi pada kecepatan lain, hasil respon dinamis ditunjukkan pada tabel 4 , 5,6 dan 7 .

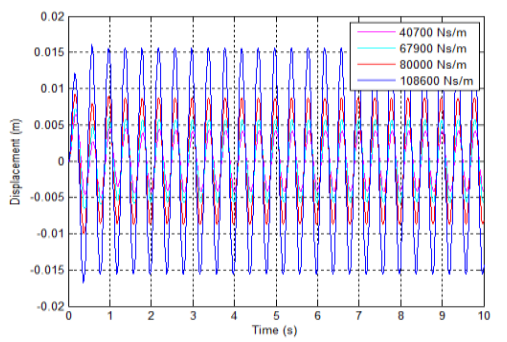

Gambar 3. Grafik respon perpindahan terhadap waktu pada sistem seperempat kendaraan $(\mathrm{V}=90 \mathrm{~km} / \mathrm{jam})$.

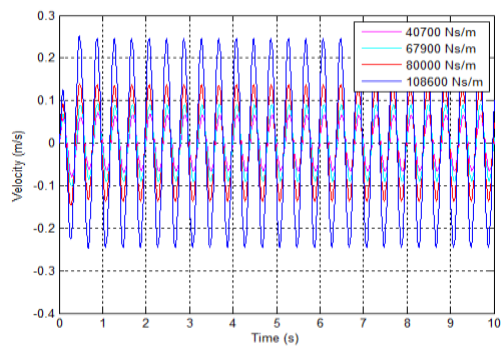

Gambar 4. Grafik respon kecepatan terhadap waktu pada sistem seperempat kendaraan $(\mathrm{V}=90 \mathrm{~km} / \mathrm{jam})$.

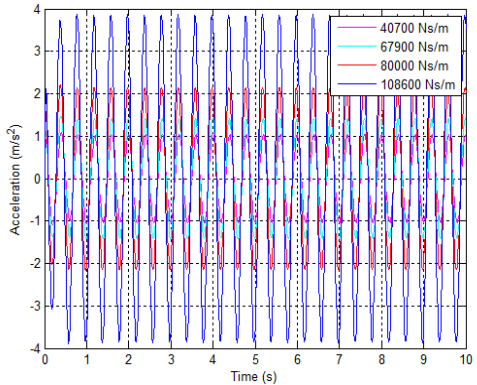

Gambar 5. Grafik respon percepatan terhadap waktu pada sistem seperempat kendaraan $(\mathrm{V}=90 \mathrm{~km} / \mathrm{jam})$.

Tabel 4.

Nilai respon dinamis simulasi seperempat kendaraan $(\mathrm{V}=20 \mathrm{~km} / \mathrm{jam})$

\begin{tabular}{cccc}
\hline \hline $\begin{array}{l}\text { Variasi } \\
(\mathrm{Ns} / \mathrm{m})\end{array}$ & $\begin{array}{c}\text { Perpindahan } \\
\text { Maksimum }(\mathrm{m})\end{array}$ & $\begin{array}{c}\text { Kecepatan } \\
\text { Maksimum } \\
(\mathrm{m} / \mathrm{s})\end{array}$ & $\begin{array}{c}\text { Percepatan } \\
\text { Maksimum } \\
\left(\mathrm{m} / \mathrm{s}^{2}\right)\end{array}$ \\
\hline 40700 & 0,0219 & 0,0763 & 0,2665 \\
67900 & 0,0203 & 0,0708 & 0,2473 \\
80000 & 0,0198 & 0,069 & 0,2408 \\
108600 & 0,0186 & 0,0647 & 0,2258 \\
\hline \hline
\end{tabular}


Tabel 5.

Nilai respon dinamis simulasi seperempat kendaraan ( $\mathrm{V}=40 \mathrm{~km} / \mathrm{jam})$

\begin{tabular}{cccc}
\hline \hline $\begin{array}{l}\text { Variasi } \\
(\mathrm{Ns} / \mathrm{m})\end{array}$ & $\begin{array}{c}\text { Perpindahan } \\
\text { Maksimum }(\mathrm{m})\end{array}$ & $\begin{array}{c}\text { Kecepatan } \\
\text { Maksimum }(\mathrm{m} / \mathrm{s})\end{array}$ & $\begin{array}{c}\text { Percepatan } \\
\text { Maksimum } \\
\left(\mathrm{m} / \mathrm{s}^{2}\right)\end{array}$ \\
\hline 40700 & 0,025 & 0,1705 & 1,1704 \\
67900 & 0,0224 & 0,1564 & 1,0882 \\
80000 & 0,0246 & 0,1718 & 1,3608 \\
108600 & 0,0248 & 0,1739 & 1,8048 \\
\hline \hline
\end{tabular}

Tabel 6.

Nilai respon dinamis simulasi seperempat kendaraan (V=60 km/jam)

\begin{tabular}{cccc}
\hline \hline $\begin{array}{c}\text { Variasi } \\
(\mathrm{Ns} / \mathrm{m})\end{array}$ & $\begin{array}{c}\text { Perpindahan } \\
\text { Maksimum }(\mathrm{m})\end{array}$ & $\begin{array}{c}\text { Kecepatan } \\
\text { Maksimum }(\mathrm{m} / \mathrm{s})\end{array}$ & $\begin{array}{c}\text { Percepatan } \\
\text { Maksimum } \\
\left(\mathrm{m} / \mathrm{s}^{2}\right)\end{array}$ \\
\hline 40700 & 0,0101 & 0,1018 & 1,0368 \\
67900 & 0,0116 & 0,1268 & 1,2724 \\
80000 & 0,016 & 0,1692 & 1,698 \\
108600 & 0,0247 & 0,2587 & 2,7067 \\
\hline \hline
\end{tabular}

Tabel 7.

Nilai respon dinamis simulasi seperempat kendaraan $(\mathrm{V}=80 \mathrm{~km} / \mathrm{jam})$

\begin{tabular}{cccc}
\hline \hline $\begin{array}{c}\text { Variasi } \\
(\mathrm{Ns} / \mathrm{m})\end{array}$ & $\begin{array}{c}\text { Perpindahan } \\
\text { Maksimum }(\mathrm{m})\end{array}$ & $\begin{array}{c}\text { Kecepatan } \\
\text { Maksimum }(\mathrm{m} / \mathrm{s})\end{array}$ & $\begin{array}{c}\text { Percepatan } \\
\text { Maksimum } \\
\left(\mathrm{m} / \mathrm{s}^{2}\right)\end{array}$ \\
\hline 40700 & 0,0074 & 0,0753 & 1,0485 \\
67900 & 0,0084 & 0,099 & 1,4117 \\
80000 & 0,0104 & 0,1495 & 2,0559 \\
108600 & 0,019 & 0,2625 & 3,649 \\
\hline \hline
\end{tabular}

Tabel 8 .

\begin{tabular}{cccc}
\hline \multicolumn{4}{c}{ Nilai respon dinamis simulasi seperempat kedaraan $(\mathrm{V}=90 \mathrm{~km} / \mathrm{jam})$} \\
$\begin{array}{c}\text { Variasi } \\
(\mathrm{Ns} / \mathrm{m})\end{array}$ & $\begin{array}{c}\text { Perpindahan } \\
\text { Maksimum }(\mathrm{m})\end{array}$ & $\begin{array}{c}\text { Kecepatan } \\
\text { Maksimum }(\mathrm{m} / \mathrm{s})\end{array}$ & $\begin{array}{c}\text { Percepatan } \\
\text { Maksimum } \\
\left(\mathrm{m} / \mathrm{s}^{2}\right)\end{array}$ \\
\hline 40700 & 0,0064 & 0,0719 & 1,0805 \\
67900 & 0,0072 & 0,0922 & 1,4609 \\
80000 & 0,0092 & 0,1402 & 2,2067 \\
108600 & 0,0161 & 0,2529 & 3,8747 \\
\hline \hline
\end{tabular}

\section{B.Perbandingan RMS (Root Mean Square) Percepatan Setiap Variasi Sistem Seperempat Kendaraan}

Pada simulasi ini digunakan standar kenyamanan ISO 2631 untuk menganalisis optimalisasi sistem suspensi sekunder dalam ketahanan berkendara akibat eksitasi sinusoidal yang terjadi. Dengan menggunakan standar tersebut dapat diketahui lama ketahanan saat berkendara.

Simulasi dilakukan dengan variasi kecepatan $10 \mathrm{~km} / \mathrm{jam}$ hingga $100 \mathrm{~km} / \mathrm{jam}$ dengan kenaikan setiap $10 \mathrm{~km} / \mathrm{jam}$. Dari kecepatan tersebut akan diperoleh nilai frekuensi dalam satuan $\mathrm{Hz}$ menggunakan persamaan $f=\frac{\mathbb{V}}{\mathbb{X}}$, dengan mengasumsikan nilai $\lambda$ (panjang jalan) sebesar $10 \mathrm{~m}$. Setelah itu, nilai RMS percepatan hasil simulasi yang terdapat pada tabel 9, akan diplot pada grafik kenyamanan ISO 2631. Pada gambar 6 dapat diketahui plotting RMS percepatan kendaraan terhadap frekuensi kendaraan untuk mengetahui ketahanan berdasarkan ISO 2631.
Berdasarkan grafik ISO 2631 pada gambar 6, kendaraan dengan variasi konstanta redaman paling kecil, yakni 40700 $\mathrm{Ns} / \mathrm{m}$ memiliki ketahanan yang paling tinggi pada frekuensi $1,389 \mathrm{~Hz}$ hingga $2,778 \mathrm{~Hz}$, atau setara dengan kecepatan 50 $\mathrm{km} / \mathrm{jam}$ hingga $100 \mathrm{~km} / \mathrm{jam}$. Dari analis is ketahanan berkendara, dapat disimpulkan untuk kedua sistem suspensi bahwa semakin bertambahnya kecepatan maka respon ketahanan berkendara semakin menurun. Nilai respon ketahanan kendaraan dapat diketahui pada Tabel 10.

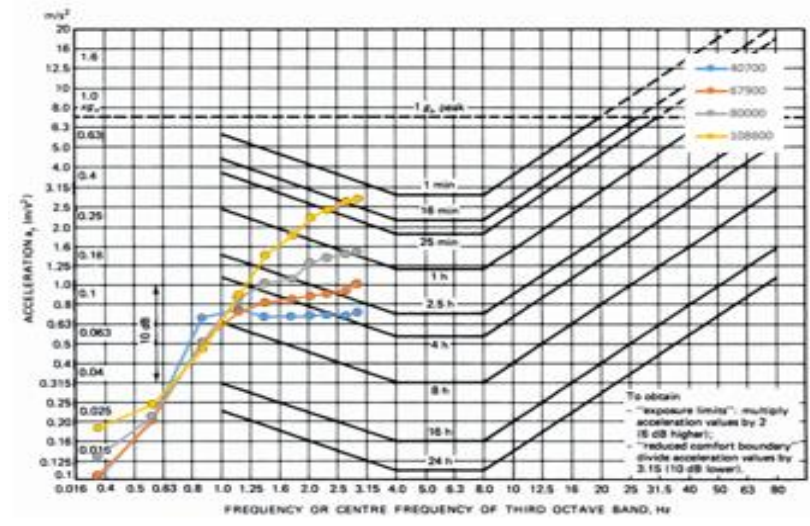

Gambar 6. Grafik ketahanan berkendara berdasarkan ISO 2631.

Tabel 9.

Nilai RMS percepatan dari sistem seperempat kendaraan

\begin{tabular}{|c|c|c|c|c|c|}
\hline \multirow[b]{2}{*}{$\begin{array}{l}\text { Kecepatan } \\
(\mathrm{km} / \mathrm{jam})\end{array}$} & \multirow[b]{2}{*}{$\begin{array}{c}\text { Frekuensi } \\
(\mathrm{Hz})\end{array}$} & \multicolumn{4}{|c|}{ RMS Percepatan $\left(\mathrm{m} / \mathrm{s}^{2}\right)$} \\
\hline & & $\begin{array}{c}40700 \\
\text { Ns/m }\end{array}$ & $\begin{array}{l}67900 \\
\mathrm{Ns} / \mathrm{m}\end{array}$ & $\begin{array}{l}80000 \\
\mathrm{Ns} / \mathrm{m}\end{array}$ & $\begin{array}{c}108600 \\
\mathrm{Ns} / \mathrm{m}\end{array}$ \\
\hline 10 & 0,278 & 0,0952 & 0,1055 & 0,1383 & 0,19 \\
\hline 20 & 0,556 & 0,2174 & 0,2062 & 0,2208 & 0,2498 \\
\hline 30 & 0,833 & 0,6623 & 0,5078 & 0,5045 & 0,4807 \\
\hline 40 & 1,111 & 0,7636 & 0,74 & 0,8363 & 0,884 \\
\hline 50 & 1,389 & 0,6663 & 0,8042 & 1,0398 & 1,4018 \\
\hline 60 & 1,667 & 0,6402 & 0,8349 & 1,1539 & 1,877 \\
\hline 70 & 1,944 & 0,6472 & 0,8724 & 1,2588 & 2,2427 \\
\hline 80 & 2,222 & 0,6736 & 0,9135 & 1,3544 & 2,4608 \\
\hline 90 & 2,5 & 0,7107 & 0,9593 & 1,4569 & 2,6059 \\
\hline 100 & 2,778 & 0,7516 & 1,0004 & 1,5469 & 2,6766 \\
\hline
\end{tabular}

Tabel 10 .

Perbandingan nilai ketahanan berkendara setiap variasi konstata redaman

\begin{tabular}{ccccc}
\hline \hline \multirow{2}{*}{$\begin{array}{c}\text { Kecepatan } \\
(\mathrm{km} / \mathrm{jam})\end{array}$} & 40700 & 67900 & 80000 & 108600 \\
& $\mathrm{Ns} / \mathrm{m}$ & $\mathrm{Ns} / \mathrm{m}$ & $\mathrm{Ns} / \mathrm{m}$ & $\mathrm{Ns} / \mathrm{m}$ \\
\hline 10 & $>24 \mathrm{jam}$ & $>24 \mathrm{jam}$ & $>24 \mathrm{jam}$ & $>24 \mathrm{jam}$ \\
20 & $>24 \mathrm{jam}$ & $>24 \mathrm{jam}$ & $>24 \mathrm{jam}$ & $>24 \mathrm{jam}$ \\
30 & $8,3 \mathrm{jam}$ & $11,5 \mathrm{jam}$ & $11,8 \mathrm{jam}$ & $12 \mathrm{jam}$ \\
40 & $6,5 \mathrm{jam}$ & $6,2 \mathrm{jam}$ & $5,7 \mathrm{jam}$ & $5,6 \mathrm{jam}$ \\
50 & $6,5 \mathrm{jam}$ & $4,7 \mathrm{jam}$ & $4 \mathrm{jam}$ & $2,2 \mathrm{jam}$ \\
60 & $5,5 \mathrm{jam}$ & $4 \mathrm{jam}$ & $2,6 \mathrm{jam}$ & 1 jam \\
70 & $5 \mathrm{jam}$ & $3,2 \mathrm{jam}$ & $1,8 \mathrm{jam}$ & 30 menit \\
80 & $4 \mathrm{jam}$ & $2,7 \mathrm{jam}$ & $1,5 \mathrm{jam}$ & 26 menit \\
90 & $4 \mathrm{jam}$ & $2,5 \mathrm{jam}$ & 1 jam & 16 menit \\
100 & $3,5 \mathrm{jam}$ & 2 jam & 1 jam & 16 menit \\
\hline \hline
\end{tabular}




\section{C.Perbandingan RMS Perpindahan Setiap Variasi Sistem Suspensi Seperempat Kendaraan}

Grafik pada gambar 7 menunjukkan hasil simulasi RMS perpindahan pada sistem seperempat kendaraan kereta api dengan penggunaan variasi konstanta redaman sistem suspensi sekunder dan disimulasikan pada variasi kecepatan kendaraan $10 \mathrm{~km} / \mathrm{jam}$ hingga $100 \mathrm{~km} / \mathrm{jam}$ dengan kenaikan setiap $10 \mathrm{~km} / \mathrm{jam}$ dan dengan mengasumsikan $\lambda$ (panjang jalan) sebesar $10 \mathrm{~m}$.

Dari grafik pada gambar 7 dan tabel 11 dapat disimpulkan bahwa pada kecepatan $50 \mathrm{~km} / \mathrm{jam}$ hingga $100 \mathrm{~km} / \mathrm{jam}$, kendaraan dengan sistem suspensi dengan konstanta redaman sebesar $40.700 \mathrm{Ns} / \mathrm{m}$ memiliki nilai yang cenderung paling baik jika dibandingkan dengan sistem suspensi variasi lainnya karena memiliki nilai RMS perpindahan yang paling rendah.

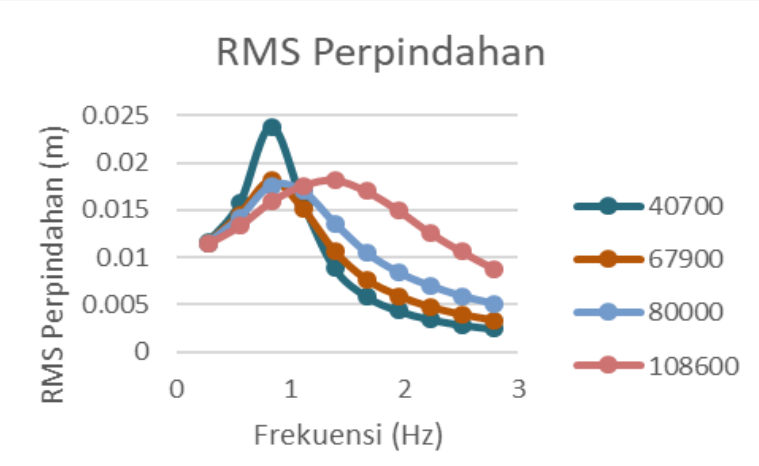

Gambar 7. Perbandingan RMS perpindahan dari respon kendaraan yang menggunakan sistem seperempat kendaraan.

Tabel 11.

Nilai RMS perpindahan dari sistem seperempat kendaraan

\begin{tabular}{cccccc}
\hline \hline \multirow{2}{*}{$\begin{array}{c}\text { Kecepatan } \\
(\mathrm{km} / \mathrm{jam})\end{array}$} & $\begin{array}{c}\text { Frekuensi } \\
(\mathrm{Hz})\end{array}$ & $\begin{array}{c}40700 \\
\mathrm{Ns} / \mathrm{m}\end{array}$ & $\begin{array}{c}67900 \\
\mathrm{Ns} / \mathrm{m}\end{array}$ & $\begin{array}{c}80000 \\
\mathrm{Ns} / \mathrm{m}\end{array}$ & $\begin{array}{c}108600 \\
\mathrm{Ns} / \mathrm{m}\end{array}$ \\
\hline 10 & 0,278 & 0,0116 & 0,0115 & 0,0115 & 0,0114 \\
20 & 0,556 & 0,0157 & 0,0145 & 0,0142 & 0,0133 \\
30 & 0,833 & 0,0238 & 0,0181 & 0,0176 & 0,0159 \\
40 & 1,111 & 0,0158 & 0,0151 & 0,017 & 0,0176 \\
50 & 1,389 & 0,0089 & 0,0106 & 0,0136 & 0,0182 \\
60 & 1,667 & 0,0059 & 0,0076 & 0,0105 & 0,017 \\
70 & 1,944 & 0,0044 & 0,0059 & 0,0084 & 0,015 \\
80 & 2,222 & 0,0035 & 0,0047 & 0,007 & 0,0126 \\
90 & 2,5 & 0,0029 & 0,0039 & 0,0059 & 0,0106 \\
100 & 2,778 & 0,0025 & 0,0033 & 0,0051 & 0,0088 \\
\hline \hline
\end{tabular}

\section{Bode Diagram}

Grafik pada gambar 8 menunjukkan bode diagram dari hasil simulasi pada sistem seperempat kendaraan kereta api dengan penggunaan variasi konstanta redaman suspensi sekunder yang disimulasikan pada variasi frekuensi dengan satuan rad/s dan dengan mengasumsikan $\lambda$ (panjang jalan) sebesar $10 \mathrm{~m}$.

Pada gambar 8 tersebut, menunjukkan gain dari sistem seperempat kendaraan kereta api dalam bentuk amplitudo dari masing-masing variasi nilai koefisien redaman. Amplitudo tertinggi terjadi pada saat frekunsi natural pertama terjadi yakni sebesar 5,6005 rad/s, dimana dari grafik tersebut terlihat bahwa nilai koefisien redaman sebesar $108.600 \mathrm{Ns} / \mathrm{m}$ merupakan nilai koefisien redaman yang memiliki amplitudo terendah. Namun, kereta api tipe $\mathrm{K} 3$ di Indonesia memiliki kecepatan rata-rata 90 $\mathrm{km} / \mathrm{jam}$, dimana frekuensi kerjanya yakni sebesar $2,5 \mathrm{~Hz}$ atau setara dengan $15,7079 \mathrm{rad} / \mathrm{s}$. Pada frekuensi tersebut, nilai koefisien redaman yang memiliki amplitudo terendah yakni $40.700 \mathrm{Ns} / \mathrm{m}$. Sehingga koefisien redaman sebesar $40.700 \mathrm{Ns} / \mathrm{m}$ dipilih sebagai acuan untuk pemilihan diameter orifice yang baru.

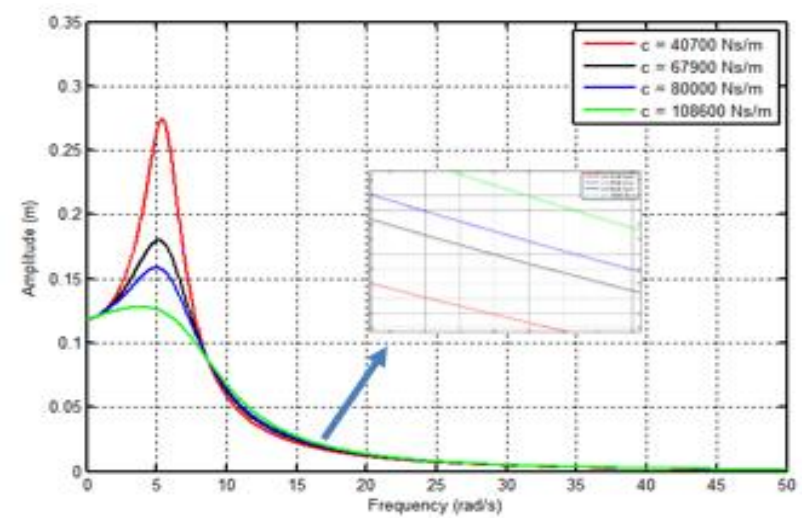

Gambar 8. Bode diagram dari sistem seperempat kendaraan.

\section{E. Respon Dinamis Sistem Suspensi Sekunder}

Setelah membahas hasil respon dari simulasi sistem seperempat kendaraan kereta api dan mendapatkan nilai konstanta redam yang paling baik, langkah selanjutnya yakni membahas respon dari simulasi sistem suspensi sekunder untuk mendapatkan diameter orifice yang paling sesuai.

Pada gambar 9 dan tabel 12 menunjukkan respon gaya redam ekspansi maupun kompresi terhadap perpindahan dan kecepata. Berdasarkan grafik dan tabel tersebut, dapat disimpulkan bahwa semakin besar frekuensi maka gaya redam yang dihasilkan semakin besar. Hal ini sesuai dengan teori pada persamaan $f=\underline{x}$, bahwa frekuensi (f) berbanding lurus dengan kecepatan (v), dan kecepatan $(x)$ juga berbanding lurus dengan gaya redam $(\mathrm{Fd})$, sesuai dengan teori pada persamaan $F d=c x$. Berdasarkan rumusan gaya redam $(\mathrm{Fd})$, didapatkan nilai koefisien redam yang terdapat pada Tabel 13.

Berdasarkan tabel 13 diameter 2,368 $\mathrm{mm}$ sesuai dengan nilai kosntanta redaman $40.700 \mathrm{Ns} / \mathrm{m}$. Oleh karena itu, diameter orifice tersebut sesuai dengan yang dibutuhkan pada sistem seperempat kendaraan kereta api tipe ekonomi (K3).

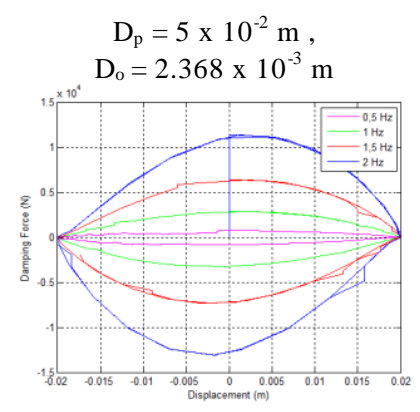

(a)

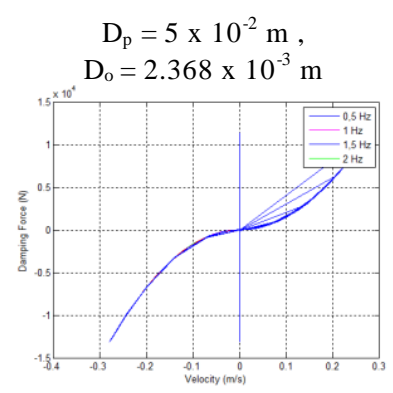

(b)
Gambar 9. Grafik respon gaya redam pada sistem suspensi (a) perpindahan, (b) kecepatan. 
Tabel 12.

Nilai gaya redam maksimum pada masing-masing diameter orifice $\left(D_{0}=\right.$

$$
\text { 1-3 mm) }
$$

\begin{tabular}{|c|c|c|c|c|c|c|c|c|}
\hline \multirow{2}{*}{$\begin{array}{c}\text { Dia } \\
\text { Orifice } \\
\left(\mathrm{D}_{0}\right)\end{array}$} & \multicolumn{9}{|c|}{ Gaya Redam } \\
\cline { 2 - 9 } & \multicolumn{2}{|c|}{$0,5 \mathrm{~Hz}$} & \multicolumn{2}{c|}{$1 \mathrm{~Hz}$} & \multicolumn{2}{c|}{$1,5 \mathrm{~Hz}$} & \multicolumn{2}{c|}{$2 \mathrm{~Hz}$} \\
\hline 1 & 25730 & 22390 & 103310 & 89250 & 230700 & 201290 & 411200 & 357980 \\
\hline 2 & 1608 & 1399.5 & 6457 & 5578 & 14410 & 12581 & 25700 & 22374 \\
\hline 2.368 & 818.4 & 712.15 & 3285 & 2838 & 7337 & 6402 & 13080 & 6401.7 \\
\hline 3 & 317.6 & 276.44 & 1275 & 1102 & 2848 & 2485 & 5077 & 4419 \\
\hline
\end{tabular}

Tabel 13.

Nilai Konstanta Redaman pada Masing-Masing Diameter Orifice

\begin{tabular}{cc}
\hline \hline Diameter Orifice $(\mathrm{m})$ & Konstanta Redaman $(\mathrm{Ns} / \mathrm{m})$ \\
\hline 0,001 & 1.280 .800 \\
0,002 & 80.050 \\
0,002368 & 40.710 \\
0,003 & 15.812 \\
\hline \hline
\end{tabular}

\section{KESIMPULAN}

a. Respon perpindahan, kecepatan, dan percepatan yang dialami oleh kendaraan untuk konstanta redam 40700
Ns/m memiliki nilai yang paling baik jika dibandingkan variasi konstanta redam lainnya pada kecepatan 50 $\mathrm{km} / \mathrm{jam}$ hingga $100 \mathrm{~km} / \mathrm{jam}$.

b. Berdasarkan grafik kenyamanan ISO 2631 ketahanan kendaraan dengan sistem seperempat kendaraan kereta api dengan variasi nilai koefisien redaman paling kecil memiliki nilai yang terbaik, yakni $40700 \mathrm{Ns} / \mathrm{m}$.

c. Semakin kecil nilai diameter orifice yang digunakan pada sistem suspensi, akan menghasilkan gaya redam yang semakin besar pula.

d. Diameter orifice 2,368 $\mathrm{mm}$ merupakan diameter yang sesuai untuk digunakan pada sistem suspensi seperempat kendaraan dengan konstanta redaman sebesar 40700 $\mathrm{Ns} / \mathrm{m}$.

\section{DAFTAR PUSTAKA}

[1] A. W. Kencono, Handbook of Energy \& Economic Statistics of Indonesia. Jakarta: Pusdatin ESDM, 2014. 